\title{
Population's health study as a factor of resource saving
}

\author{
Natalia Astafieva ${ }^{1}$, Natalia Ivanova $^{2}$, Elena Dorozhkina ${ }^{3}$, and Ruslan Minnullin ${ }^{4 *}$ \\ 1,2 Yuri Gagarin State Technical University of Saratov, Polytechnicheskaya St., 77, Saratov, 410054, \\ Russia \\ ${ }^{3}$ Balakovo branch of RANEPA, Chapaeva St., 107, Balakovo, 413865, Russia \\ ${ }^{4}$ Industrial University of Tyumen, Volodarskogo St., 38, Tyumen, 625000, Russia
}

\begin{abstract}
The article presents an approach to factor monitoring of health status of the population, based on a system of indicators used in international comparisons and in the labor and energy resources management system. This methodical approach is supplemented by indicators, taking into account specifics of the issue being studied (mortality at working age and incidence of socially-related diseases). Integrated health index of the population is calculated, the degree of its dependence on the constituent components is revealed, an assessment of the effectiveness of social policy instruments for saving labor resources in health care has been carried out when implementing the concept of innovative development of the country and the energy management system.
\end{abstract}

\section{Introduction}

Saving quantitative and qualitative characteristics of labor resources is one of the priorities of the state social policy at the present stage of economic development. This is objectively due to three factors. Firstly, there is catastrophic decline in population. For example, in Russia, the population has decreased from 148, 6 million people. in 1993 to 146.3 million people. in 2018, including those of working age, from 89.8 to 82.2 million people, respectively, and the proportion of retired citizens is currently 37.3 million [1]. The mortality rate of the working-age population in Russia is 2.5 times higher than the average mortality rate in the country and 4.5 times more than similar indicator in the EU countries [2]. Secondly, current negative trends in health status, which is an initial component in shaping quality of labor resources. Third factor is adoption of the law on raising the retirement age in Russian Federation, providing for an increase in retirement age for Russians by 5 years, from 60 to 65 years for men and from 55 to 60 years for women. Transition to the new values will be implemented gradually, starting from January 1, 2019.

Currently, health as a global and social problem is among the priority issues of state social policy. The complexity of problems associated with savings and functioning of the

\footnotetext{
* Corresponding author: minnullin400@yandex.ru
} 
main productive force of society, their importance for solving tasks of economic development of the country led to the relevance of this study.

At present, there are no comprehensive studies of issues of saving labor resources in Russia. The purpose of the article is to assess effectiveness of social policy instruments for saving labor resources in health care and in energy management system, which is based on the algorithm for calculating the integral indicator - the index of health of labor resources, which made it possible to identify the degree of dependence of this complex indicator on the components, to determine its development trends information base that allows to make effective decisions to neutralize negative trends in development of this process at all levels of its regulation.

Many studies are devoted to the issue of saving labor resources. Conceptual approaches of the authors depend on the goals and objectives of the study. The authors focus on certain aspects of this problem: Rimashevskaya N.M. [2] (considers saving at the macro level population health, at the micro level - individual health, individual health potential, determining differences in indicators, fixation objects, specific factors impact on savings and formation; reveals an organic relationship with the causes that determine the state of individual health of the workforce; the object of the regulatory impact of the state is formation of a culture of self-protection anxiety behavior, overcoming poverty and social polarization in society); Suvorova V.V. [3] (savings at the level of the municipality; the object of regulation is the population of the municipality), Zemlyanukhina S.G. [4] (the process of saving the population is the object of the regulatory influence of the state: the subject of regulation is income differentiation), Danilova N.V. [5] (considers saving of labor resources at the enterprise level, the object of regulation is health of industrial workers), Lavrentyeva I.V., Ilyshev A.M. (savings at the household level; the object of regulatory influence on the part of the state is reproduction process and domestic reproductive labor), Buryakov S.A. considers the process of saving labor resources in the aspect of modernization of the system of their reproduction, through formation and functioning of the institute of renovation, etc. [5]. Analysis of the sources on this issue revealed the presence of different approaches to its solution, but with a certain difference of views, the authors agree: saving the people health is the main task of the state [2].

The initial idea underlying the authors' approach to the stated issue is the understanding that in the state policy priorities structure, the state should consider health of labor resources and rational use of energy resources as part of national wealth, since this is a key factor contributing to increased productivity, growth of gross domestic product, determining the strength of the state and improving the welfare of society. In strategic terms, this should be a decisive condition for implementation of the concept of innovative development of the country in conjunction with dealing with issues on implementation of energy policy and achievement of goals to improve the efficiency of energy saving.

\section{Methods}

In international practice, two complementary approaches are used to assess the level of public health. The first one is health state assessment through demographic indices of longevity (LE) and infant mortality, synthesizing many aspects of the quality of life (health, lifestyle, income level of the population and living conditions). The second one is the use of indicators of the prevalence of social diseases (tuberculosis, HIV / AIDS, oncology, chronic alcoholism, etc.).

Given the characteristics of demographic and social situation in the region, the authors consider it expedient to use a comprehensive method for assessing the influence of life expectancy factors (LE), infant mortality and morbidity (prevalence) of socially significant 
diseases on the health indicator used in international comparisons with addition of the mortality factor of the able-bodied population.

To calculate the population health index in the Saratov region, life expectancy indicators were chosen for men and women at birth, mortality rates at working age (men and women), infant mortality, incidence rates (prevalence) of socially-related diseases (tuberculosis, oncology, syphilis, alcoholism, addiction).

Integrated health assessment was carried out according to the following algorithm:

1) identifying indicators and compiling tables of baseline data;

2) calculation of private indices (through indicators that adversely affect the integral index of health).

The life expectancy index (life expectancy at birth) was calculated by the formula (1):

$$
I_{i}=\frac{X_{i}-X_{\text {imin }}}{X_{\text {imax }}-X_{\text {imin }}}
$$

Mortality and morbidity indices are calculated by the formula (2):

$$
I_{i}=1-\frac{X_{i}-X_{\text {imin }}}{X_{\text {imax }}-X_{\text {imin }}}
$$

$X_{i}$ - existing value of the indicator, $X_{\text {imin }}$ - minimum value of the indicator, $X_{\text {imax }}$ maximum value of the indicator.

Reference points for life expectancy: 25 and 85 years (according to the classical methodology of human development assessment proposed by the UN) [3]; for mortality and morbidity, the maximum and minimum values for the region for the study period (2001-2018) were selected;

3) calculation of generalized indicators of life expectancy at birth (LE), mortality of the working population.

Summarizing indicators are calculated by the formula (3):

$$
I L E_{\text {gen }}=\frac{\left(I L E_{\mathrm{men}}+I L E_{\mathrm{women}}\right)}{2}
$$

4) Health Index Calculation (4):

$$
I=\frac{\left(I L E+I_{\text {mort.children }}+I_{\text {mort.adult }}+I_{\text {morb }}\right)}{4}
$$

Baseline data for the calculation are presented in table 1.

Table 1. Baseline data for the calculation of indicators of the health index and its components

\begin{tabular}{|c|c|c|c|c|c|c|c|}
\hline Indicator & Units & $\mathbf{2 0 0 1}$ & $\mathbf{2 0 0 4}$ & $\mathbf{2 0 0 8}$ & $\mathbf{2 0 1 2}$ & $\mathbf{2 0 1 6}$ & $\mathbf{2 0 1 8}$ \\
\hline \multirow{2}{*}{$\begin{array}{c}\text { average life } \\
\text { expectancy }\end{array}$} & Gen & 65.8 & 65.7 & 67.9 & 70.2 & 71.9 & 72.1 \\
\cline { 2 - 8 } & Men & 59.9 & 58.9 & 61.2 & 64.5 & 66.5 & \\
\cline { 2 - 8 } & Women & 71.8 & 71.3 & 72.3 & 73.9 & 77.0 & \\
\hline $\begin{array}{c}\text { Mortality of the able } \\
\text { bodied population } \\
\text { per 1000 people }\end{array}$ & Men & 12.4 & 13.4 & 12.5 & 12.1 & 8.9 & 7.3 \\
\cline { 2 - 9 } & Women & 2.8 & 3.6 & 2.6 & 2.8 & 2.2 & 2.1 \\
\hline $\begin{array}{c}\text { Infant mortality per } \\
\text { 1000 people }\end{array}$ & $\%$ & 14.8 & 10.1 & 8.5 & 8.6 & 7.1 & 6.4 \\
\hline Oncology & Cases & 276 & 328 & 321 & 295 & 194.4 & 195.1 \\
\hline Tuberculosis & Csses & 62.4 & 72.3 & 53.6 & 44.6 & 42.1 & 39.2 \\
\hline Alcoholism & Cases & 105 & 130 & 116 & 117 & 127 & 131 \\
\hline
\end{tabular}




\begin{tabular}{|c|c|c|c|c|c|c|c|} 
Syphilis & Cases & 175 & 96.3 & 64.9 & 55 & 51 & 54 \\
\hline Drug Addiction & cases & 45.9 & 20.1 & 9 & 6.6 & 6.2 & 6.1 \\
\hline
\end{tabular}

\section{Results}

The results of the adjusted health indices and their constituent elements are presented in Figure 1.

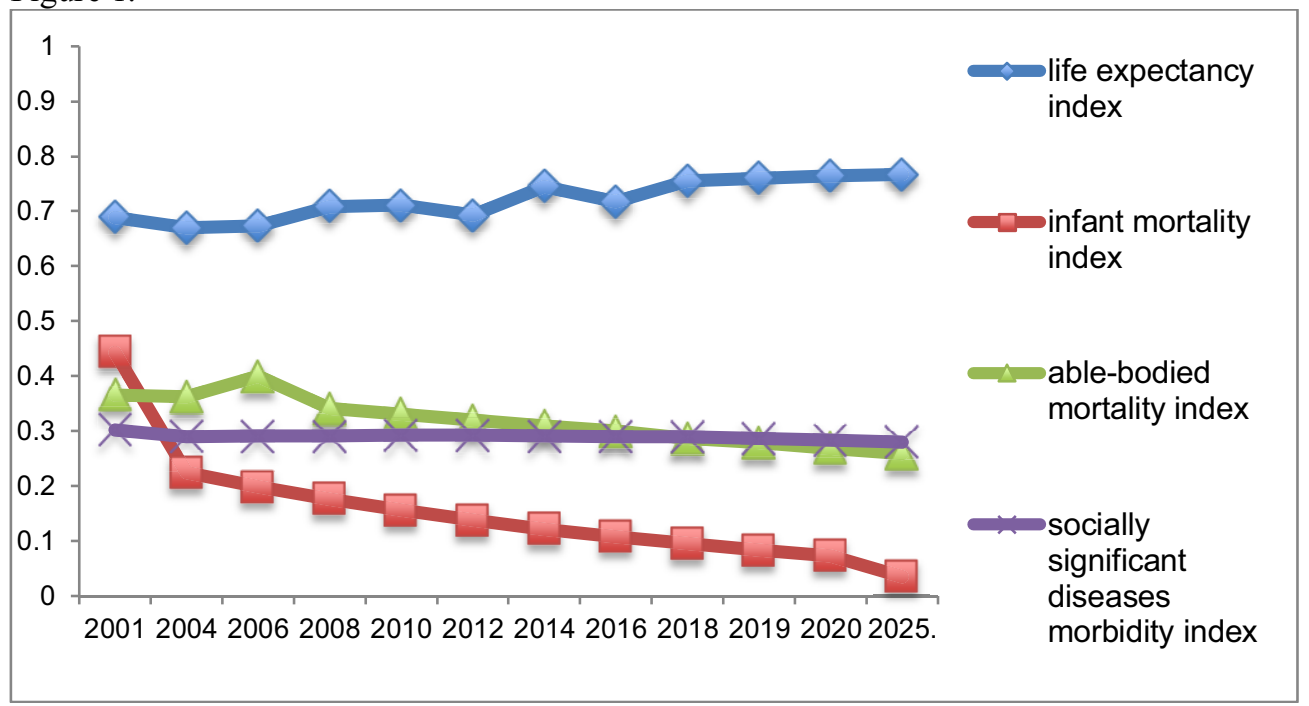

Fig. 1. Value of the elements of the health index

Period from 2001 to 2004 is characterized by a decrease in the health index. The low level of public health in the Saratov region is associated with a high infant mortality rate, which in some years was higher than the average for Russia (in 2003-2004: 19.9-19.5 per 1,000 births, in Russia - 12.3-11.6, respectively per 1000 births) [1]. During this period, a decrease in the health index of the able-bodied population was also observed.

From 2005 to 2018 there is an increasing trend pattern. This is due to the holding of large-scale public policy measures aimed at raising the standard of living of the population, in particular, improving the quality and accessibility of health services. As part of the implementation of the national project "Health", strengthened medical measures were taken to intensify public health care: an increase in the priority primary health care, an increase in the preventive nature of health care, and an increase in the availability of high-tech medical care. The region participates in the Rural Doctor project. To overcome the negative demographic trends in the region, the project "Technologies and Comfort for Mothers and Children" is being implemented, aimed at preserving health of the population, including the reproductive age [1].

The increase in the health index is explained by the increase in life expectancy, a decrease in infant mortality, mortality of the working-age population, and a decrease in incidence of drug addiction. However, oncological morbidity is increasing, which significantly increases the overall incidence of socially-related diseases. Since 2019, a new modern oncology center has been built in Saratov, equipped with high-tech equipment to achieve better treatment results by reducing the risk of organ damage and reducing hospital stay.

To determine relations between life expectancy indices, morbidity index and mortality index (of working-age and infant population) and their effect on health index, correlation 
coefficients were calculated. Since it is necessary to investigate changes in the indices over time, deviations of the levels of the indices from the trend values were used as correlating indicators. This adjustment is due to the fact that direction and value of the trend are influenced by long-term causes, and fluctuations in values relative to the trend are affected by short-term factors, their identification is one of the objectives of this study.

As the type of the equation, a 3rd degree polynomial was chosen, its equation has the formula (5):

$$
Y=a_{0}+a_{1} \times X+a_{2} \times X^{2}+a_{3} \times X^{\wedge} 3
$$

In the Excel program there were calculated paired correlation coefficients, presented in Table 2 .

Table 2. Correlation coefficients of the health index and its components

\begin{tabular}{|c|c|c|c|}
\hline $\begin{array}{c}\text { Components } \\
\text { Index }\end{array}$ & $\begin{array}{c}\text { Incidence of social } \\
\text { diseases }\end{array}$ & $\begin{array}{c}\text { Life } \\
\text { expectancy }\end{array}$ & $\begin{array}{c}\text { Infant and able-bodied } \\
\text { mortality }\end{array}$ \\
\hline Health index & 0.008635 & 0.2355 & 0.989236 \\
\hline
\end{tabular}

The data presented in table 2 indicates that the greatest relations are observed between the health index and the cumulative infant mortality rate and the mortality rate of the working-age population. Among the dead at working age, men make up $80 \%$, which is 4 times the death rate of women. If such a mortality rate continues in the future among boys who have reached the age of 16 , every third boy will not live to retirement age [3].

Despite the smallest correlation between the index of health and morbidity, the latter indicator is significant for assessing the health of the population, since for such socially significant diseases as oncology and HIV, the area exceeds the average Russian indicators. The correlation relations between the complex incidence rate indicator and its particular components are presented in Table 3.

Table 3. Correlation coefficients of the incidence index of socially-related diseases

\begin{tabular}{|c|c|c|c|c|c|}
\hline Index Components & Oncology & Tuberculosis & Alcoholism & Syphilis & $\begin{array}{c}\text { Drug } \\
\text { addiction }\end{array}$ \\
\hline $\begin{array}{c}\text { Prevalence of socially- } \\
\text { related diseases }\end{array}$ & 0.467029 & -0.288421 & -0.089117 & -0.442151 & -0.732181 \\
\hline
\end{tabular}

As can be seen from table 3, the greatest closeness is observed between the generalized incidence rate of socially-related diseases and the incidence of drug addiction, at the 2nd place is the relationship with the disease of syphilis, at the 3rd - cancer incidence. Despite the low indices of incidence rates of drug addiction and syphilis, they significantly affect the prevalence rate of socially significant diseases, therefore, special control over the level of these indicators is necessary.

Life expectancy tends to increase since 2005. The negative dynamics of life expectancy, which is an important characteristic of the quality of public health, has long been determined by high rates of infant mortality and mortality at working age, which indicates a decline in attention to prevention and deterioration of diagnosis and quality of treatment.

The analysis showed that the infant mortality index has a pronounced downward trend from 2004 to current moment, which was made possible thanks to the implementation of the national project "Health", the federal target program "Children of Russia", the program "Birth certificate", "Technology and comfort - mothers and children ", aimed at supporting motherhood and protecting the health of the child, introduction of one hundred percent neonatal screening for identification of congenital and hereditary diseases in newborns. 
In addition, in the region there is a slight decrease in the mortality of the working population. Despite the fact that the overall trend has a downward appearance, since 2006 there has been an increase in mortality among the female population, which may lead to a change in the direction of the trend in the future. The demographic situation also remains tense due to the fact that in the structure of total mortality about half of the deaths occur in the working-age population, which adversely affects the current demographic situation, as well as future socio-economic development of the territory.

Such a high mortality rate at working age is predetermined by an increase in total and primary morbidity of practically all the most important socially-related diseases tuberculosis, drug addiction, chronic alcoholism, HIV infection and malignant neoplasms (Table 1), since According to the data of socio-statistical studies, carriers of this kind of diseases are overwhelmingly people of working age.

The overall incidence rate of socially-related diseases tends to increase (the incidence rate index is positive $(0.0003>0)$ ). The increase in incidence is influenced by the positive dynamics of oncological morbidity, alcoholism, and tuberculosis. The incidence of drug addiction and syphilis correct the incidence index in direction of reducing.

Trend health index on the basis of identified trends for the period 2001-2018 forecast until 2025 is presented in Figure 2.

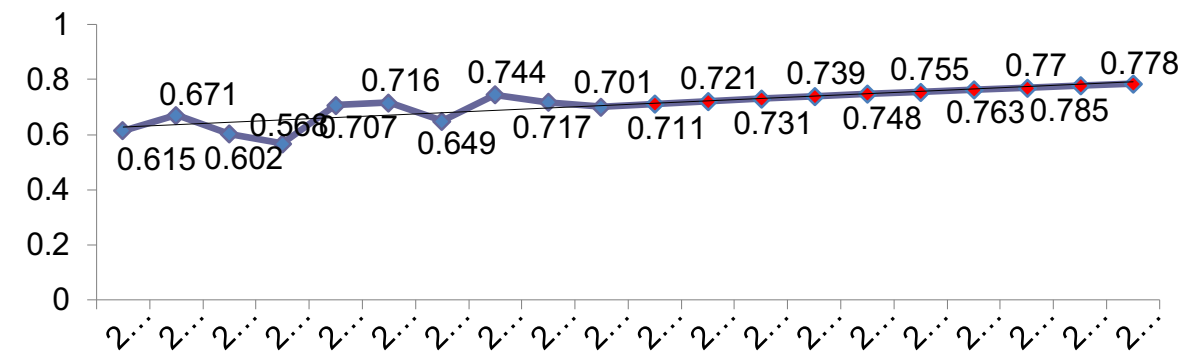

Fig. 4. Forecast health index based on identified trends until 2025

Over the past five years, life expectancy in the Saratov region has increased by 1.8 years and reached 71.7 years. At the same time, the death rate among people of working age at the end of 2016 decreased by $9 \%$. The infant mortality rate was 6.4 cases per 1,000 live births, which is $5.9 \%$ below the target ( 6.8 per thousand), which suggests a continuing positive trend [6].

\section{Discussion}

It is necessary to take into account that healthcare is only one of the components of the effective management process at an enterprise, which is to recognize the increase at the current stage of the share of responsibility of health care as a sector for the state of public health, varying from $8-10$ to $30-45 \%$ of total set of factors affecting it socio-economic, behavioral, hereditary-genetic, climatic and other genesis. The issues of public health and well-being of individuals and local communities as a whole, as well as achievement of goals set for the implementation of a policy of saving labor and energy resources are multifactorial and require comprehensive approach to their solution. The actions of local governments taken in accordance with existing legislation, specific area of responsibility and direct official duties affect many of the determinants of health.

For the future of the country, it is necessary to realize the priority of improving the state of health and protecting the population's health, as well as to implement a set of interrelated measures aimed at shaping social policy of saving labor and energy resources, 
setting goals and developing measures to achieve these goals. It is strategically important to integrate the solution of the problem of public health and management of labor and energy resources into the processes of socio-economic development of society, since the ultimate goal of national economy is to maximize the output to the social sphere. Therefore, only a person-centered economy can be truly effective, ensuring both preservation and improvement of the quality of human resources.

\section{Conclusion}

Analysis of the state of health of the population allowed us to draw following conclusions.

By the size of the integral index of health of labor resources and combination of the components of its components of life expectancy indices, infant mortality, mortality at working age and morbidity of socially-related diseases, the Saratov region belongs to the group of territories with an average level of population health, incl. able-bodied, tending to increase. To compare the indices, we used the information base presented in the statistical compilations of Rosstat. Given the high morbidity of the population, high mortality and low life expectancy, there is a need to take additional measures to create conditions for improving health of the population, reducing mortality and increasing life expectancy.

Meanwhile, health care is only one of the components of the effective management process, which is to recognize the increase at the current stage of the share of responsibility of health care as a sector for the state of public health, varying from 8-10 to $30-45 \%$ of the total affecting factors of socio-economic, behavioral, hereditary-genetic, climatic and other genesis. The problems of public health and well-being of individuals and local communities in general are multifactorial and require a comprehensive approach to their solution.

It is necessary to take urgent measures to ensure the growth of responsibility and interest in improving health of people in all sectors of economy and management at all levels. This will be possible if the health indicators of population are among the main ones in evaluating activities of each manager in any sector of economy, and the head of the region will be responsible for development of public health at the regional level.

In conclusion, it should be noted that the issues of public health and efficient use of labor and energy resources are multifactorial and, in the light of a long-term development strategy in modern conditions, require comprehensive approach: implementation of priority socially oriented economic policies in the field of health and energy saving, which takes into account the importance of specific government programs guaranteeing improved health and development for future generations; taking serious measures in the field of energy use, ecology and human environment; widespread promotion of healthy lifestyle and sanitary and hygienic standards with effective methods of promoting health. In strategic terms, this should be a decisive condition for implementation of the concept of innovative development of the country in conjunction with dealing with issues on implementation of energy policy and achievement of goals set to improve the use of labor and energy resources.

\section{References}

1. A. A. Korneshov, Population, 1, 19-28 (2010)

2. N. M. Rimashevskaya, Population, 1, 4-10 (2010)

3. V. V. Suvorova, Development of human resources in the conditions of formation of a social state, 110-121 (2009) 
4. S. G. Zemlyanukhina. Development of human resources in the conditions of formation of a social state, 178-201 (2009)

5. N. V. Danilova, Social aspects of public health, 4 (2008)

6. N. V. Zubarevich, Social development of Russian regions: problems and trends of the transition period, 264 (2007) 